\title{
A New Statistic Approach towards Landslide Hazard Risk Assessment
}

\author{
George Gaprindashvili ${ }^{1,2 *}$, Jianping Guo ${ }^{3}$, Panisara Daorueang ${ }^{4}$, Tian Xin ${ }^{5}$, Pooyan Rahimy ${ }^{6}$ \\ ${ }^{1}$ Department of Geology, National Environmental Agency, \\ Ministry of Environment and Natural Resources Protection of Georgia, Tbilisi, Georgia \\ ${ }^{2}$ Institute of Geo-Information Science and Earth Observation (ITC) of the University of Twente, \\ Enschede, The Netherlands \\ ${ }^{3}$ Institute of Atmospheric Composition, Chinese Academy of Meteorological Sciences, Beijing, China \\ ${ }^{4}$ Department of Public Works and Town \& Country Planning, Ministry of Interior, Bangkok, Thailand \\ ${ }^{5}$ Institute of Forest Resource Information Techniques, Chinese Academy of Forestry, Beijing, China \\ ${ }^{6}$ School of Environmental Sciences, University of Guelph, Guelph, Canada \\ Email: "gaprinda1609@yahoo.com, "gaprindashvili.george@gmail.com
}

Received November 13, 2013; revised December 15, 2013; accepted January 3, 2014

Copyright (C 2014 George Gaprindashvili et al. This is an open access article distributed under the Creative Commons Attribution License, which permits unrestricted use, distribution, and reproduction in any medium, provided the original work is properly cited. In accordance of the Creative Commons Attribution License all Copyrights (C) 2014 are reserved for SCIRP and the owner of the intellectual property George Gaprindashvili et al. All Copyright (C) 2014 are guarded by law and by SCIRP as a guardian.

\section{ABSTRACT}

To quantitatively assess the landslide hazard in Khelvachauri, Georgia, the statistic method of hazard index was applied. A spatial database was constructed in Geographic Information System (GIS) including topographic data, geologic maps, land-use, and active landslide events (extracted from the landslide inventory). After that, causal factors of landslides (such as slope, aspect, lithology, geomorphology, land-use and soil depth) were produced to calculate the corresponding weights, and thereby we defined a relevant set of spatial criteria for the latter landslide hazard assessment. On top of that, susceptibility assessment was performed in order to classify the area to low, moderate and high susceptible regions. Results showed that NW aspect, mountain geomorphology, private land-use, laterite loam and clay, slope between 19 to 24 degrees, and soil depth between $10-20 \mathrm{~cm}$ were found to have the largest contribution to high landslide susceptibility. The high success rate $\mathbf{( 7 2 . 3 5 \% )}$ was obtained using area under the curve from the landslide susceptibility map. Meanwhile, effect analysis was carried out to assess the accuracy of the landslide susceptibility, indicating that the factor of slope played the most important role in determining the occurring probability of landslide although it did not deviate as much as other factors. Finally, the vulnerability analyses were carried out by means of the Spatial Multi-Criteria Estimation model, which in turn, led to the risk assessment. It turned out that not so much of the number of buildings ( $34.13 \%$ ) was associated with high-risk zone and that governmental and private land-use almost accounted for the same risk ( $39.9 \%$ and $40.9 \%$, respectively).

\section{KEYWORDS}

Landslide; Weight; Susceptibility; Vulnerability; Statistic

\section{Introduction}

Nowadays, quantitative landslide assessment is still inadequate due to too limited resources available for research, such as historic records of landslides and detailed socio-economic elements at risk. In particular, there are no enough data available in order to construct a proba-

"Corresponding author. bilistic model of landslides at different magnitudes that leads to a quantitative risk assessment. Most conventional landslide studies are descriptive and qualitative; therefore, it is imperative for data-driven assessment in combination with in-depth knowledge of all the causal factors for landslide. The quantitative approach applied in this study, is of great importance for the benefit of the government decision-makers, the urban planners and ulti- 
mately the local communities.

The landslides frequently cause huge social and economical disasters, posing threat to life and livelihood all over the world. Many environmental factors related to fields of geology, geomorphology, topography, and landuse have the potential to induce landslides [1]. Tools for handling and analyzing spatial data (i.e., GIS) facilitate the application of quantitative techniques in landslide hazard assessment and mapping. In terms of methods in evaluating a landslide hazard, they can be categorized into: geological, geotechnical, hydrological, geophysical modeling, and statistical approach.

The work of Lee and Jones [2] suggests that landslide risk assessment methods should be classified as qualitative, semi-quantitative and quantitative. The recent trend towards the development of warning systems and land utilization regulations aimed at minimizing the loss of lives and damages to properties without investing in long-term and costly projects of slope stabilization [3,4]. As a result, nowadays landslide hazard assessment, including susceptibility and vulnerability mapping, increasingly becomes vital.

Recently, various studies have been carried out on quantitative landslide susceptibility assessment along with deterministic statistics [5-7] and even artificial intelligence [8-13]. Unfortunately, the above-mentioned risk assessment methods are case-specific and require many types of data on landslide occurrence and impact, most of which, however, are not yet available in Georgia, our study area of this paper.

To identify areas that are susceptible to future landslides, it is very important to accurately detect past landslides and to quantitatively formulate the relation between the landslide occurrence and spatial occurrence of environmental data. Therefore, this paper will present a statistical method called "hazard index" to tackle the issues of landslide susceptibility and risk analysis in Khelvachauri, Georgia. This method is mainly based on the landslides inventory map, generated by visual interpretation of aerial photos, satellite images, and field surveys. Six indicator maps contributing to the occurrence of landslides will be combined as well. Susceptibility assessment in this area was also carried out, and assessed using the effect assessment. Finally, we constructed a vulnerability map by comparing the produced landslide susceptibility map with available data of elements at risk.

\section{Study Area}

The study area (Figure 1) is located in Khelvachauri, one of the five municipalities in Adjara, an autonomous republic in the southwest Georgia, $8 \mathrm{~km}$ southeast from one of the major cities of Georgia - Batumi. Also, it covers an area of about $97.5 \mathrm{~km}^{2}$ with a population of approximate 38,000 , including the city of Khelvachauri and
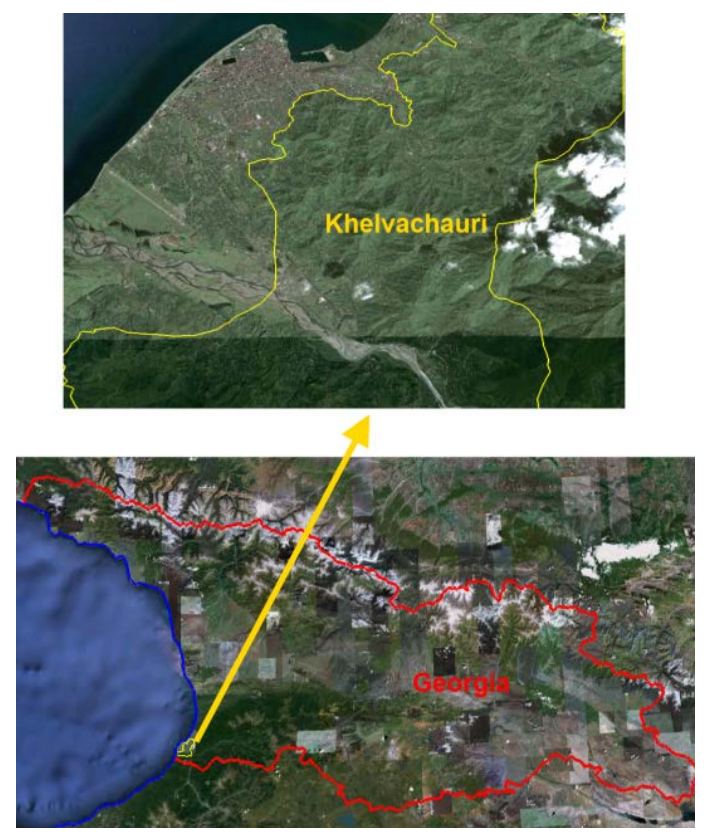

Figure 1. The study area of Khelvachauri, Georgia shown within the red boundary (Source: Google Earth).

Makhinjauri, as well as 30 villages. This area is bounded by the Black Sea to the west and by Turkey to the south. Within the study area, the most important and longest river is Chorokhi River, which flows $26 \mathrm{~km}$ along the region. Most of its parts pass through mountainous region, which is practically inaccessible for field exploration. Agriculture dominates in the regional economy although industry has been also developed. There are three tea factories, stagnant materials plant and constructing blocks workshop. However, agriculture (especially in tea and citrus production) as well as husbandry takes a leading part.

Landslides occur almost in all landscape - geomorphologic zones, which makes that there is a wide differentiation in the failure types and mechanisms and in the size-frequency distribution. Negative impact of landslides are in the form of destruction of buildings, agricultural lands, roads and other infrastructure and also to considerable effect on population in the form of loss of human life and a significant number of eco-migrants.

The relief, geology, geomorphology of the territory of Khelvachauri creates favorable conditions for the development of active geological processes, such as landslides, mudflows/debrisflows and rockfalls. Landslide processes affecting the social and economic development of the country are widespread in this region.

\section{Data Description}

In order to assess the landslide hazard triggered by rainfall in Khelvachauri, Georgia, we first have to obtain the landslide inventory map, which was limited to the period 
of 2000 to 2006, with the original landslide data from Ministry of Environmental Protection and Natural Resources of Georgia. The inventory recorded 45 landslides, almost belonging to the active states. Typically, landslides were visually interpreted by comparing ortho-rectified aerial photographs taken before and after the occurring of landslides, in conjunction with high-resolution Google-Earth images and intensive fieldwork (Figure 2). Finally we derived the landslide inventory map, including all types of landslides and their corresponding information, eg. occurring time and the degree of damage.

The causal factors and elements at risk are prerequisites for the latter risk and vulnerability assessment, which is described in detail in the following sections.

\subsection{Causal Factors}

The causes of landslides have been classified into rainfall, earthquakes, erosion weathering, groundwater level, and human activities [14]. Even though there are always more than one single cause for the occurrence of landslides, according to the records of Ministry of Environment and Natural Resources Protection of Georgia, the active landslides in this study area, nevertheless, are mainly induced by the rainfall.

In theory, the more possible causal factors considered, the more accurate landslide susceptibility and risk assessment. To this end, we tried our best to collect such data as topography, geotechnical and general soil measurements, lithology, geomorphology, and satellite images. Nonetheless, the factor of rainfall, commonly thought as a main triggering factor of landslide, was excluded primarily due to unavailability of enough weather stations. The above-mentioned factors used here were digitized based on the historical geological maps at the scale of 1:10,000. Factors derived from topography, such as slope gradient and slope aspect, were calculated from the topographic data, generally considered as the most influential factors. Furthermore, geomorphologic data

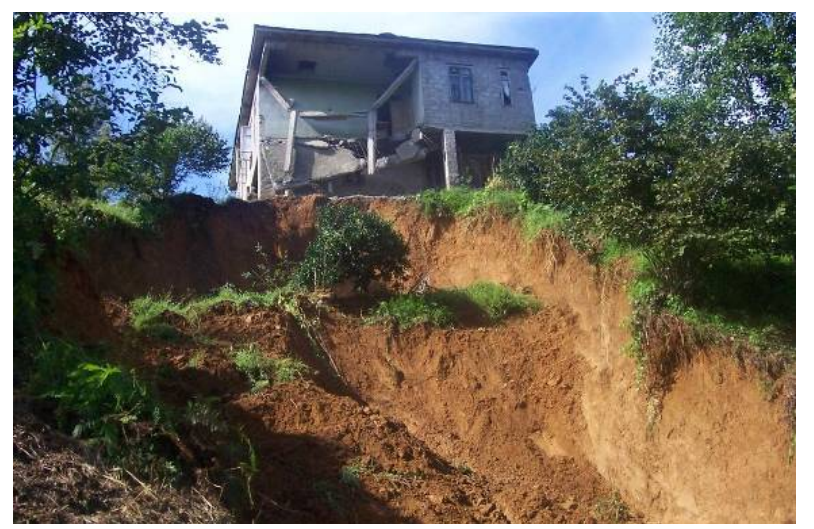

Figure 2. Landslide in Ortabatumi (Khelvachauri Municipality). were collected from historical map and the land-use data were derived from parcel data of the cadastral database. Soil depth data were measured via field survey investigation prior to landslide occurring.

\subsection{Elements at Risk}

Identifying the elements at risk of landslide and vulnerability assessment need the exact spatial distribution of buildings in the study area, as well as the socio-economic information like the number of stories, possession of properties, economic values etc. All of the data considered as elements at risk were basically extracted from cadastral data and participatory GIS procedures.

\section{Methodology}

\subsection{Workflow}

As shown in Figure 3, the workflow for the assessment of landslide can be roughly described as follows:

The primary input data were lithology, geomorphology, land use, soil depth and topographic data. Other information (secondary data) was derived from the different input data (e.g., slope and aspect from topographic). The collectively called causal factors (primary and secondary data) were used as inputs into the statistic model. This was separately calculated to give the respective weight and was finally analyzed for the susceptibility assessment. Finally, the physical vulnerability was assessed by the Spatial Multi-Criteria Estimation (SMCE) method [15] and was computed through crossing the number of building and land use information. It should be noted that results from the SMCE did facilitate the determination of physical vulnerability in this study area.

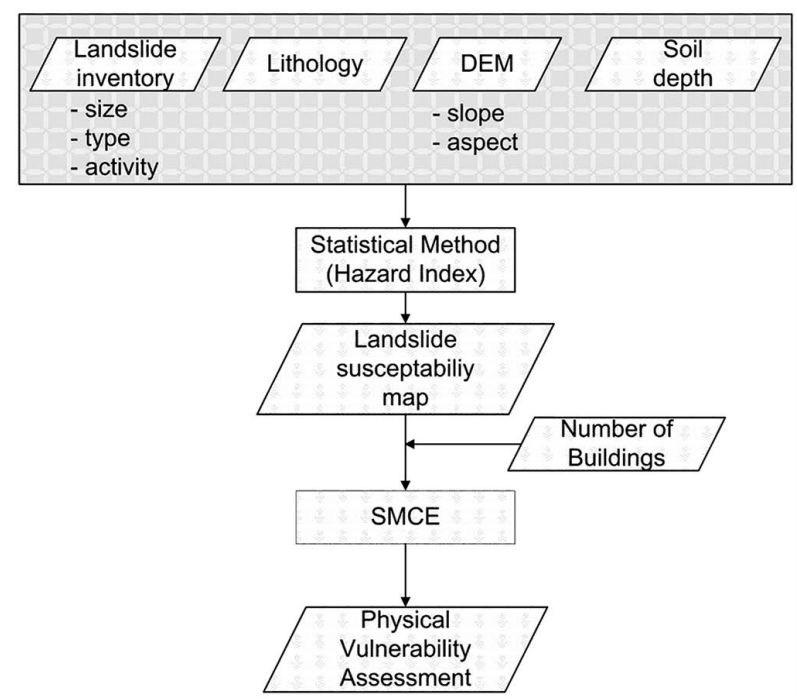

Figure 3. Flowchart of susceptibility mapping and vulnerability assessment of landslide. 


\subsection{Hazard Index Method}

Due to the lack of enough landslide history and geotechnical data, the quantitative, deterministic or probabilistic models were excluded from the study. As an alternative, bivariate statistical vulnerability assessment of landslide (a semi-quantitative approach) was applied here, just based on the active landslide events. The method explicitly considered a number of factors influencing the stability of slope [16], including the following 6 parameters: lithology, geomorphology, landuse, soil depth, slope and aspect.

In order to assess the vulnerability of landslide hazard, landslide susceptibility map was generated using a basic statistical method, called hazard index, which was formulated as:

$$
W_{i}=\ln \left[\frac{\text { Densclas }}{\text { Densmap }}\right]=\ln \left[\frac{\operatorname{Area}(\mathrm{Si})}{\operatorname{Area}(\mathrm{Ni})} / \frac{\sum \operatorname{Area}(\mathrm{Si})}{\sum \operatorname{Area}(\mathrm{Ni})}\right] \text { (1) }
$$

where $W_{i}$ represented weight, and subscript $i$ indicated one of the 6 parameters: slope, aspect, lithology, geomorphology, land use and soil depth. Densclas was the landslide density belonging to the corresponding parameter class. Densmap represented the landslide density within the entire map. "Area (Si) "indicated area, which contained landslides, for a given parameter class. Area (Ni) referred to the total area for a given parameter class. Noted that all the processes were performed in Integrated Land and Water Information System (ILWIS), which is a GIS and remote sensing software developed by The Faculty of Geo-Information Science and Earth Observation of Twente University, Netherlands.

As illustrated in Figure 4, the slope was first derived from Digital Elevation Model (DEM), and then was weighted according to Equation (1). The other five causal factor parameters can be assigned the corresponding weight in that vein. Specifically, the method was based on map by crossing landslide map at the active state with one of the 6-parameter maps. The map crossing results were shown in a cross table, which was utilized to calculate the density of landslides for a given parameter class. A standardization of these density values was obtained by relating them to the overall landslide density in the entire area. Here, the landslide density in the entire map divided the landslide density per class. The natural logarithm was taken, so it follows that when the landslide density was lower than normal, you will get negative weights, and positive when it was higher than normal.

By mathematically adding up the weights of the 6 factor maps, a susceptibility map can be created. After that, the values were classified into three classes: low, moderate and high susceptibilities. A cross validation technique called "success rate" was performed to evaluate the performance of the model. The pixels of the sum of the 6 factor maps were arranged from high to low values based on the frequency information of the histogram and were categorized into 100 classes. Subsequently, a joint frequency was calculated with the overlaid active landslide map and summed 6 factor maps and was presented as a cumulative percentage of landslides and the percentage of map's area. The area under the curve was calculated as well to assess the accuracy of the map.

Effect analysis can further show how success rate changes when the input factors are changed and quantifies the uncertainty of each factor [17]. Effect analysis was done by excluding a single factor from the summation of the other factors in such a way that for example the aspect was excluded and the weights of geomorphology, lithology, land-use, slope, and soil depth were summed up. This was repeatedly done for all the causal factors.

\section{Results}

\subsection{Causal Factors Mapping}

Terrain parameters, i.e. slope and aspect were always being thought as good indicators of the spatial criteria required in SMCE-based landslide susceptibility assessment. They were primarily derived from DEM data. From the very beginning, we tried to derive terrain parameters from two different DEM source, i.e. ASTER and topographic map. By comparing the contour line from ASTER DEM and that of the 1:50,000 topographic map, large errors were found (maximum 30 meters shift, not graphically shown here) between them. As a result, we selected DEM from topographic map as the data source for the aspect and slope factors, and cautions should be taken in the potential applications of ASTER DEM in the assessment of landslides hazard. On top of slope and aspect maps, other factors such as lithology, geomorphology, soil depth and land use were shown in Figure 5.

\subsection{Active Landslide Extraction}

Thirty-eight active landslides were extracted and taken as the dependent variable in the model thus the susceptibility assessment was performed based exactly on this type. Also, as indicated in Figure 6, the active landslides spread sporadically everywhere in the study area, which suggested that the situation in this area is very severe. Given the multi-land use types and topographic factors in this area, the assessments of landslide were getting more complicated.

\subsection{Weight Assignment}

To identify the most influential causal parameters on active landslides in the study area and quantify their cor- 


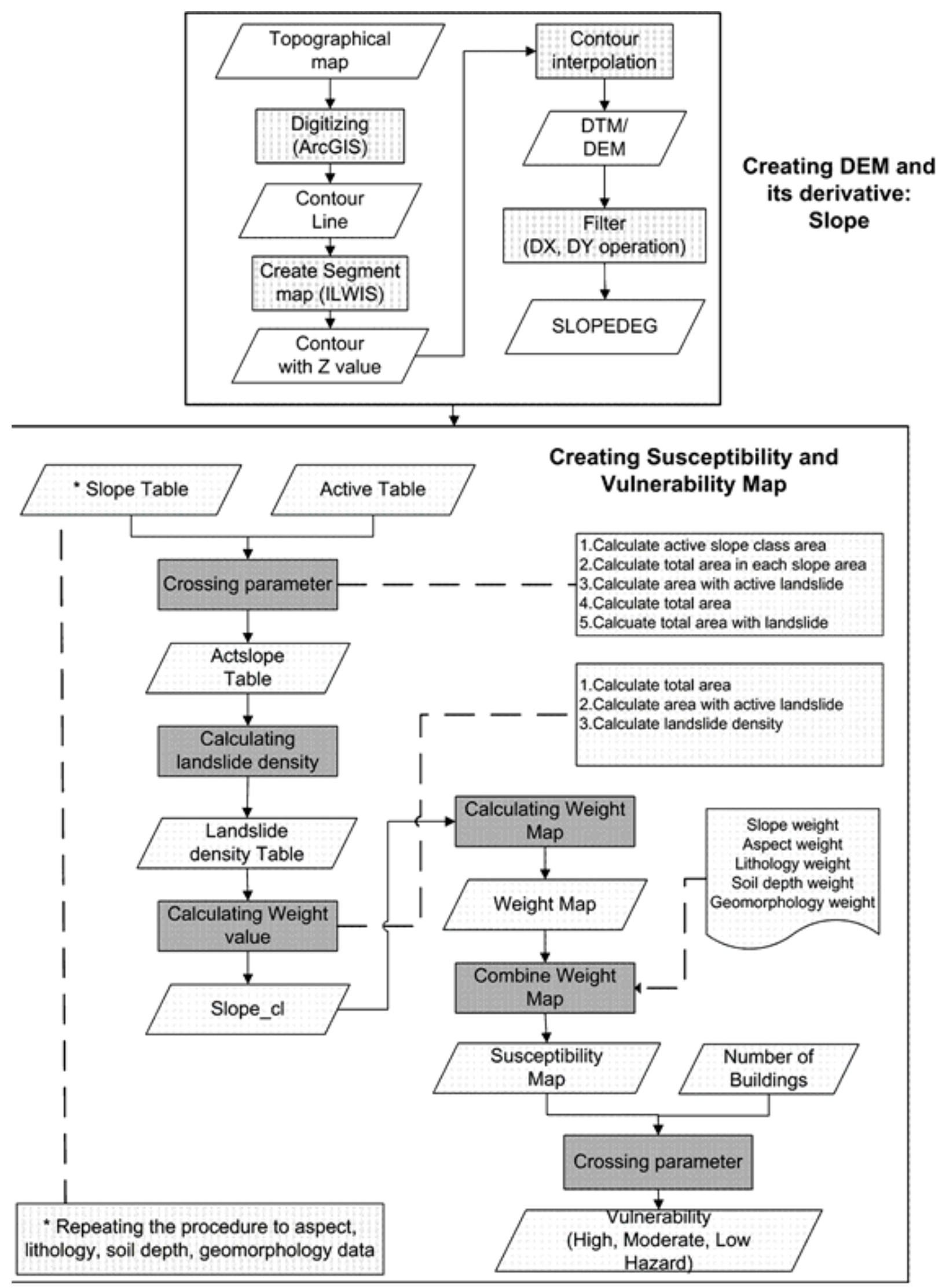

Figure 4. The detailed methodology employed in landslide assessment. 

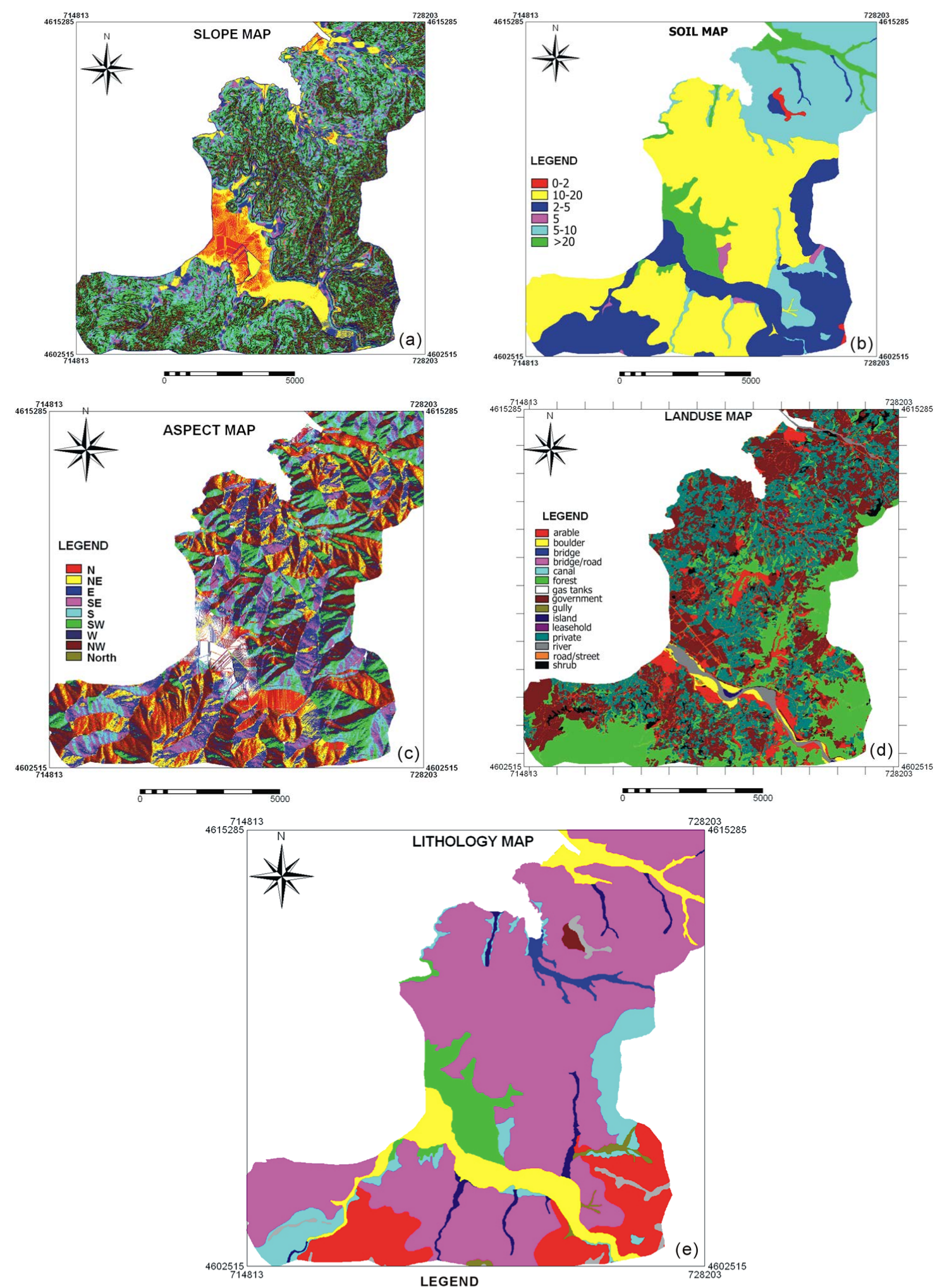

gravel with loamy filler

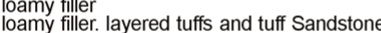

lom and clay with rubby and gruss inclusions, rubble and gruss groud with loam and clay filler

loam and clay. loam and clay with inclusions of crushed stone and gravel.

oam and clay. loam and clay with inclusions of crushed stone and grave.

loam and clay. loam and clay with rubble and gruss inclusion
rubble, gruss and clay. rudepieced (fragmented) ground (primer) loamy and sandy filler

rudefragmented (pieced) and pieced material with sandy and loamy filler

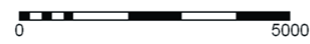




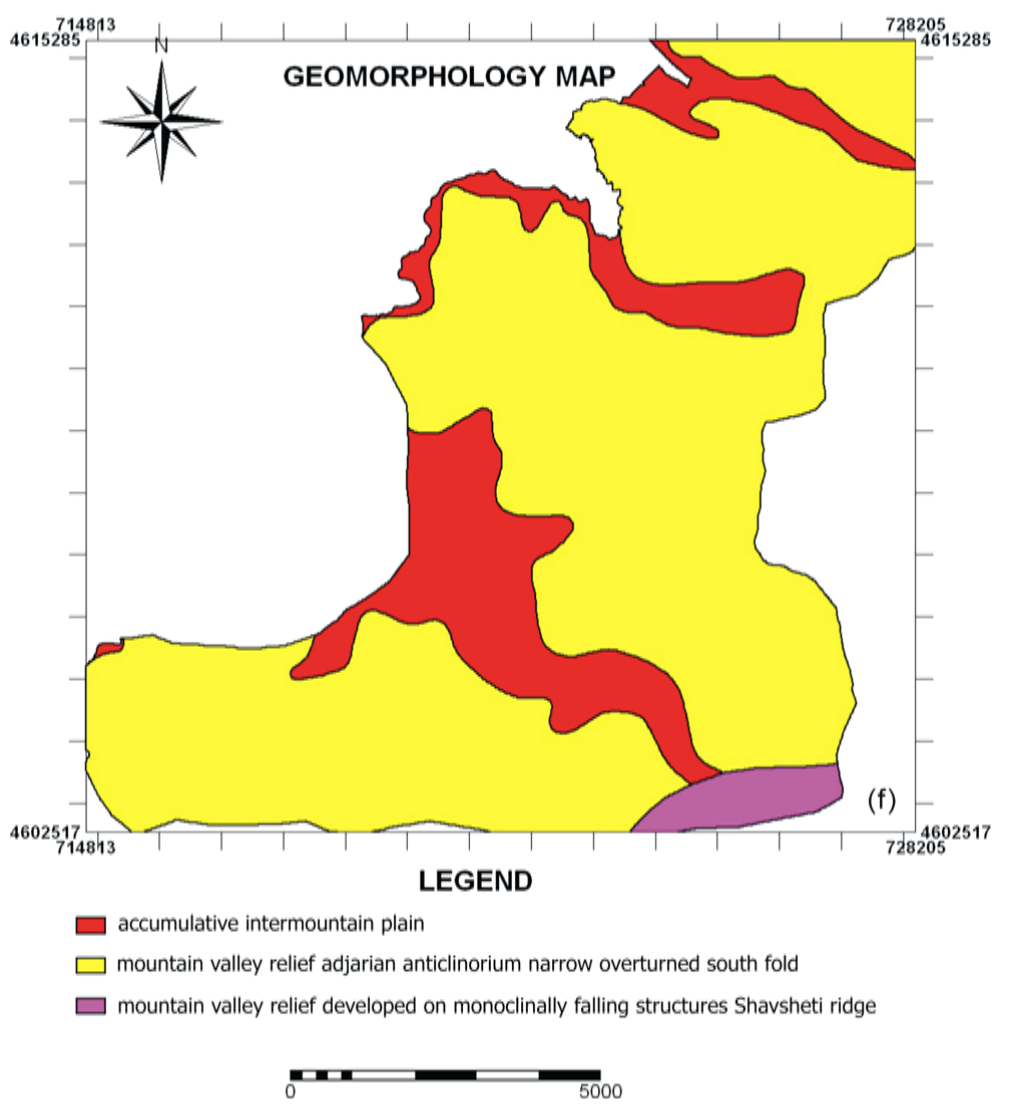

Figure 5. Causal factor maps for slope (a), soil depth (b), aspect(c), land use (d), lithology (e), and geomorphology (f), respectively.

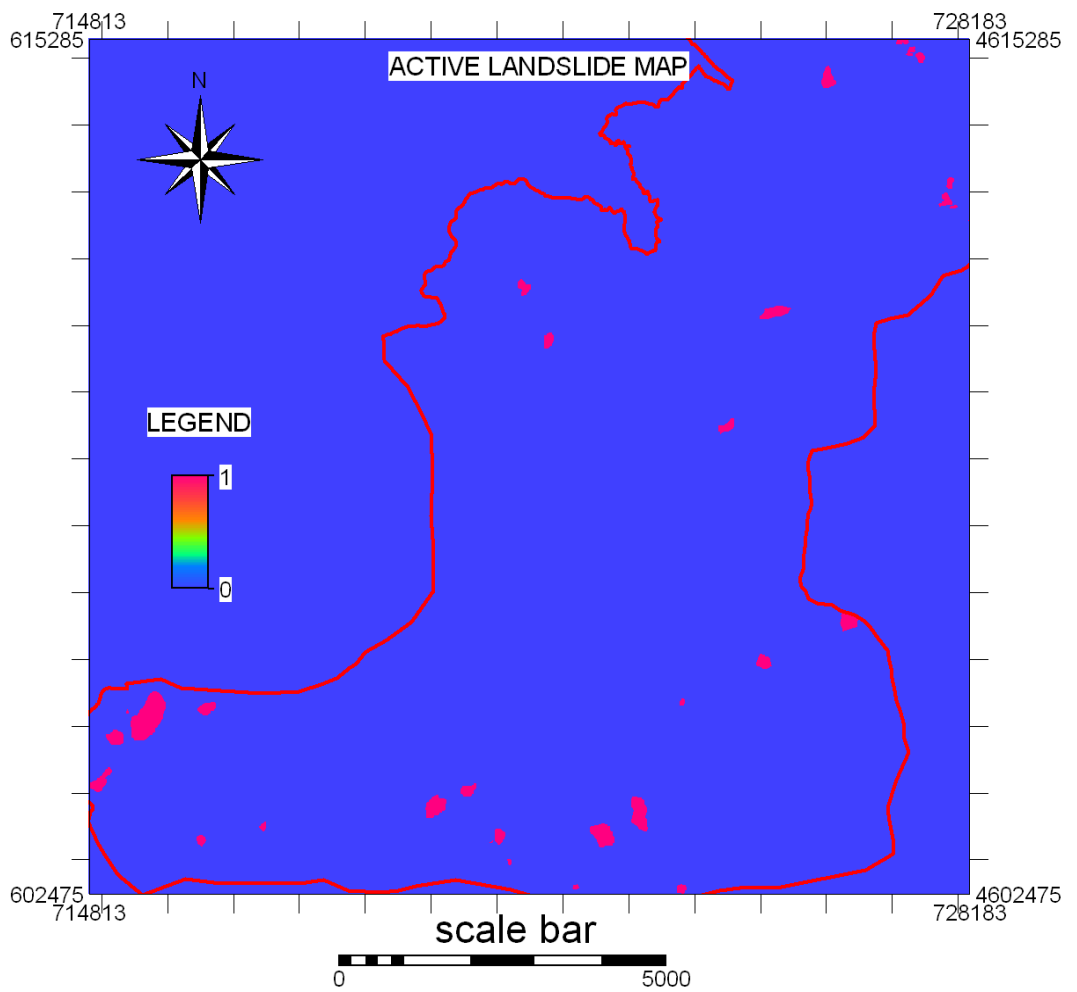

Figure 6. Active landslide events extracted from the land- slide inventory over the study area. 
responding contributions, we calculated the weight of the six parameters described in Section of Methodology using Equation (1). Various causal parameters had quite different influences on the landslide occurrence, either favorable or unfavorable [18]. The weight results for the six causal parameters were not shown here. By adding up the weight of causal factors such as slope, soil depth, geomorphology, aspect, land use and lithology, we got the overall weight map, as shown in Figure 7.

From the calculated weights in Table 1, the most important influential subtypes of causal factors related with landslide were recognized. As for the aspect factor, NW had the most important relation with landslides. The mountain class of geomorphology was more prone to landslide. Similarly, private land use and laterite loam and clay represented the highest susceptibility for landslide. The slope between 19 - 24 degrees and soil depth between $10-20 \mathrm{~cm}$ were most associated with landslide.

\subsection{Susceptibility Assessment}

Based on the weights assignment, we carried out the susceptibility assessment. The final weights of the resulting map ranged from -18.9 to 2.2. Although the weight map (Figure 7) showed good indication of the quantitative landslide hazard in the study area, too wide range might make it difficult to utilize by decision mak- ers for development planning. Therefore, the hazard map was grouped into three simplified categories based on the histogram of the final weight map (Figure 7): high, moderate and low (Figure 8). Low hazard corresponded to the range of $(-18.9,-4)$, the moderate to $(-4,1.1)$ and the high one to $(1.1,2.2)$.

The landslide susceptibility map gave the spatial distribution of the relative susceptibility values for the whole area. Figure 8 indicated that the moderate and high susceptible zones had a more disperse pattern, compared with the low susceptibility zone. Based on the susceptibility in Figure 8, we got the statistics of area or percentage of Landslide Susceptibility Classes, which was given in Table 2. Results showed that the area of $27.7 \mathrm{~km}^{2}$ (28.4\%) located in the high hazard zone, a more considerable area (53.2\% of the total area) was assigned to moderate landslide susceptibility zone.

\subsection{Assessment and Effect Analysis of Model}

The success rate curve [19] is of importance to the verification of susceptibility map of landslides, which was performed by comparing the known landslide location with the landslide susceptibility map. As such, the success rate had been applied in many previous studies $[20,21]$ to assess landslide prediction model performance.

In this paper, by assuming that the landslides were

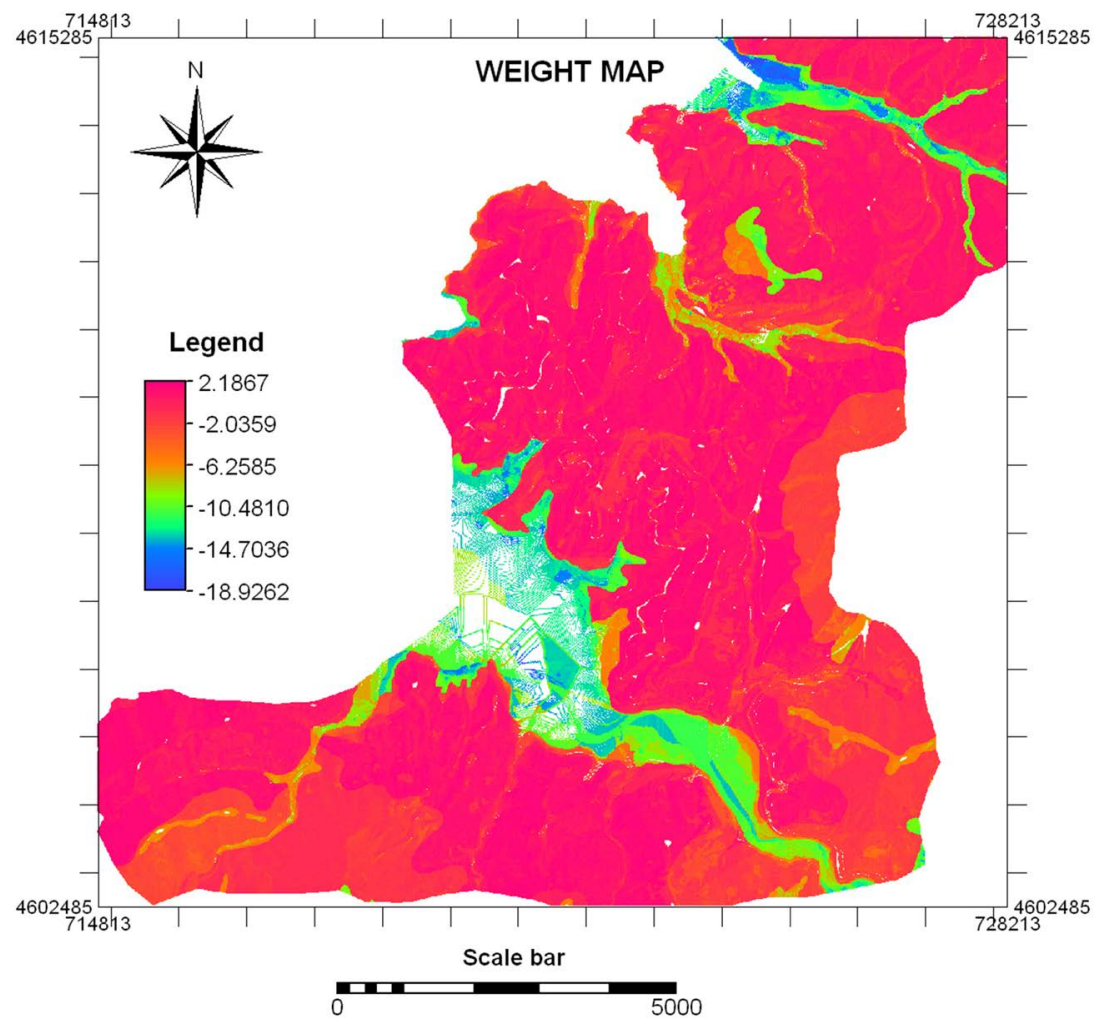

Figure 7. The overall weight produced by averaging out the weights of six causal factors. 


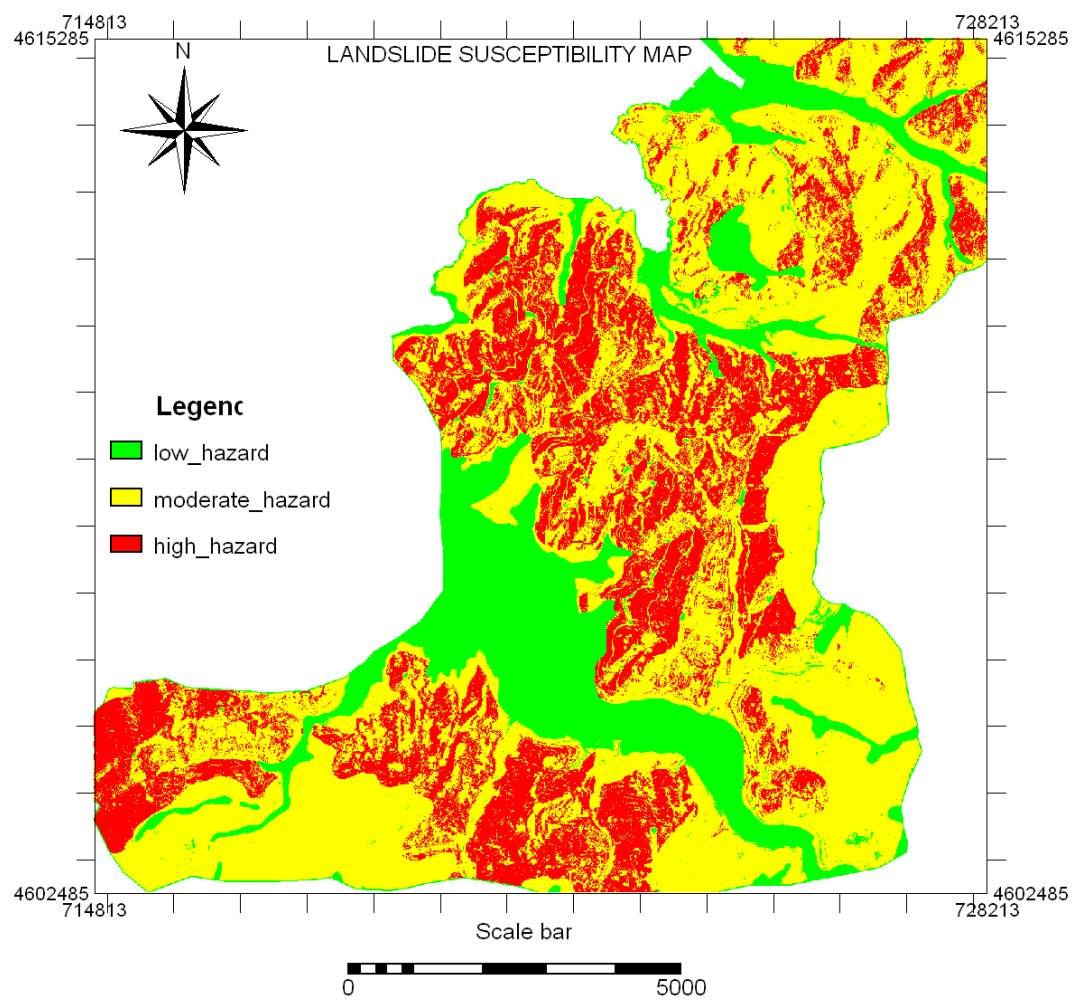

Figure 8. The susceptibility map in our study area, which was calculated from the hazard index method applied in this study.

Table 1. Most influential type or value range versus each causal factor.

\begin{tabular}{ccccccc}
\hline Causal factor & Aspect & Geomorphology & Land-use & Lithology & Slope (degree) & Soil depth (cm) \\
\hline Most influential subtypes & NW & mountain & private use & laterite loam and clay & $19-24$ & $10-20$ \\
\hline
\end{tabular}

Table 2. Area and percentage of landslide susceptibility classes.

\begin{tabular}{ccc}
\hline Classification & Area $\left.\mathbf{( k m}^{\mathbf{2}}\right)$ & $\mathbf{\%}$ \\
\hline low hazard & 18.0 & 18.4 \\
moderate hazard & 51.8 & 53.2 \\
high hazard & 27.7 & 28.4 \\
Total area & 97.5 & 100 \\
\hline
\end{tabular}

linked to the causal factors (geomorphology, slope, aspect, soil depth, land-use, and lithology) and that the excessive rainfall serves as the trigger of the event, success rate allowed an estimate of a good fit of the model through statistical computations. As shown in Figure 9(a), the obtained success rate curve was very steep in the former part, indicative of great predictive capability. Particularly, roughly $82 \%$ of the pixels predicted a $100 \%$ landslide (indicated by red B in Figure 9(a)), whereas more or less $50 \%$ of the pixels with the highest weight value in the map showed $80 \%$ landslides (indicated by blue A in Figure 9(a)).

Also, the area under the curve (AUC) was calculated to quantify the validity of the model $[22,23]$. Total area approaching 100 percent signifies perfect prediction while an area under 50 percent represented an invalid prediction. In this case, the area under the curve of the overall success rate curve was $72.35 \%$, which implied that the model was valid.

In this study, the effect analyses were conducted by exclusion of each factor in turn from the summation of the weight factors. Related success rates were drawn and the effect of each factor was evaluated using area under the curve calculation, which was given in Figure 9(b). Furthermore, there were no significant deviations of success rate curves by excluding any causal factor from the overall curve. Meanwhile, it can also be deduced from Figure 9(b) that the most important factor on landslide analysis, was the slope with AUC $=70.22 \%$, then the important factor is followed by soil depth (AUC $=71.35 \%$ ), lithology (AUC = 71.61\%), land-use (71.99\%), geomorphology (AUC $=72.73 \%)$, and the aspect $(\mathrm{AUC}=72.80 \%)$.

\subsection{Vulnerability Assessment}

Vulnerability should be considered in the physical, social, environmental dimensions. However, due to the limited 

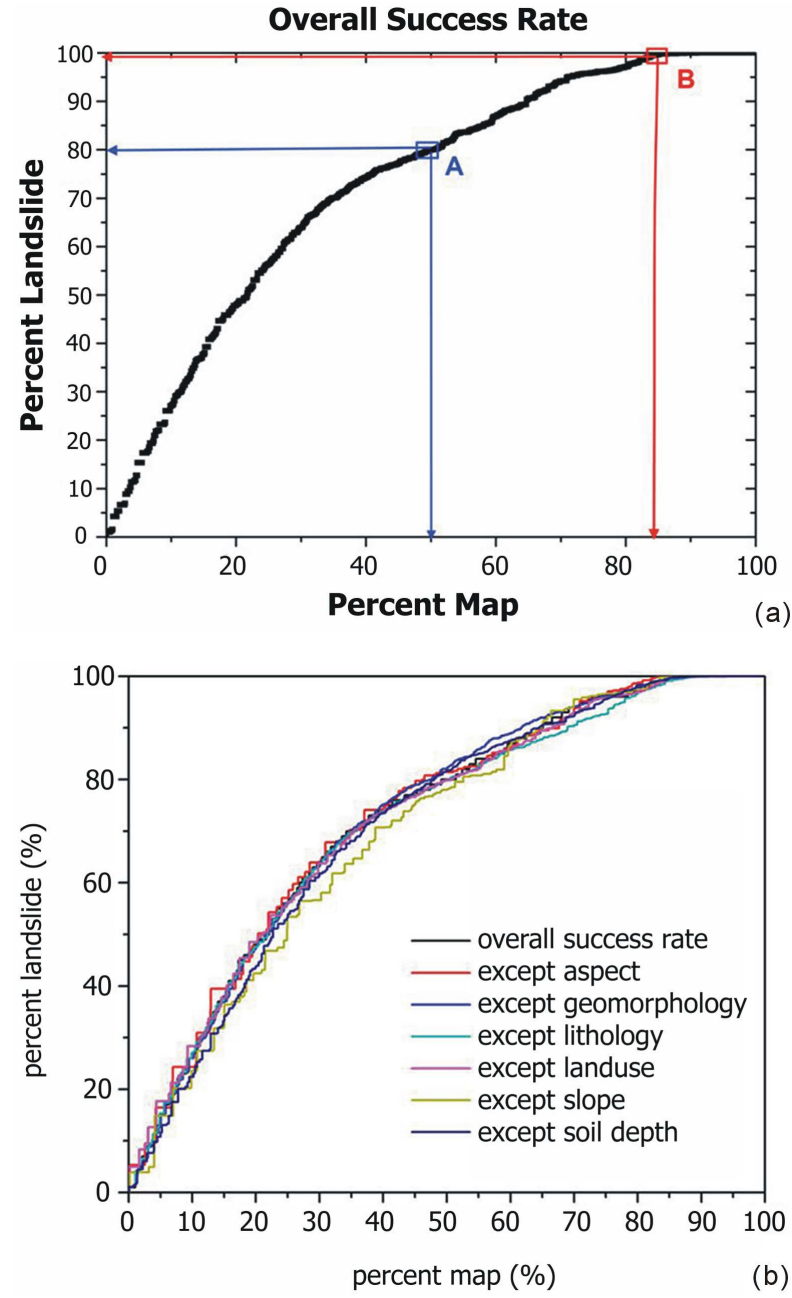

Figure 9. Calculated overall success rate based on six causal factors (a), superimposed by the effect analysis results (b), which was performed by exclusion of each factor every time.

availability of data related to population and social properties, the physical vulnerability assessment has only been performed. The physical vulnerability was assessed based on elements at risk of building and land-use.

The assessment results were given in Table 3 . Within this study area, a total number of 9909 buildings were included. Amongst them, 3382 buildings (34.13\%) represented high susceptibility class, followed by 4584 buildings as moderate susceptible.

According to Table 4, within in study area, main land use types were categorized as either private or public owned by government. As for low susceptibility class with an area of $17.9 \mathrm{~km}^{2}$, the governmental land use accounts for about $26 \%$ and private about $23.3 \%$. In moderate susceptibility class, with an area of $51.9 \mathrm{~km}^{2}$, the governmental land use accounts for about $26.6 \%$, and private about $25.6 \%$. For the high susceptibility class with an area of $27.6 \mathrm{~km}^{2}$, the governmental and private
Table 3. Physical vulnerability results (number of buildings).

\begin{tabular}{ccc}
\hline Susceptibility classifications & Number of buildings & Percentage \\
\hline High susceptibility & 3382 & 34.13 \\
Moderate susceptibility & 4584 & 46.26 \\
Low susceptibility & 1943 & 19.61 \\
Total & $\mathbf{9 9 0 9}$ & $\mathbf{1 0 0}$ \\
\hline
\end{tabular}

Table 4. Physical vulnerability results (land use).

\begin{tabular}{ccc}
\hline Hazard * Landuse & Area $\left(\mathbf{k m}^{\mathbf{2}}\right)$ & $\mathbf{\%}$ \\
\hline Low hazard * government & 4.7 & 26.0 \\
Low hazard * private & 4.2 & 23.3 \\
Total Low susceptibility class area & 17.9 & \\
Moderate hazard * government & 13.9 & 26.6 \\
Moderate hazard * private & 13.3 & 25.6 \\
Total Moderate susceptibility class area & 51.9 & \\
\hline High hazard * government & 11.0 & 39.9 \\
High hazard * private & 11.3 & 40.9 \\
Total High susceptibility class area & 27.7 & \\
Total area of Khelvachauri & $\mathbf{9 7 . 5}$ & \\
\hline
\end{tabular}

land use accounts for $39.9 \%$ and $40.9 \%$, respectively.

\section{Discussion and Conclusions}

The results showed that despite the operational and conceptual limitations, landslide hazard assessment should be a suitable, cost-effective aid to land-use planning and hazard reduction.

By calculating the respective weight for six different causal factors, it was recognized the area with NW aspect, mountain geomorphology, private land-use, laterite loam and clay, 19 - 24 degree for slope and soil depth between 10 and $20 \mathrm{~cm}$ were among the most susceptible areas for landslide occurrence. Primarily due to the lack of reliable and high-resolution rainfall fields, few statistical models have included rainfall variables as explanatory variables. This was also the reason that this research did not take into account the rainfall as an approach for the landslide hazard and risk assessment. Moreover, the analysis was done in terms of physical vulnerability (by overlaying the number of buildings, including land-use data, in the different hazardous areas).

Landslide susceptibility maps are of great importance to planners and engineers for choosing suitable locations to implement eco-social developments. In this study, we found that about $28.4 \%$ of the area was prone to high landslide risk.

The final landslide susceptibility map, with the combination of all the weights, yielded a satisfactory prediction of the landslide with a success rate of $82 \%$. The role 
of geomorphology, soil depth, lithology, and slope served as very important factors for the landslide processes. The models were proven valid through the calculation of the area under the curve, i.e., all success rate curves occupy more than $72.35 \%$ of the total area. Effect analysis showed that slope played the most important role in the landslide analysis since slope bore the greatest weight. Therefore when all factor weights were added except for the weight of the slope, the resultant weight greatly diminished which in turn reduced the percentages of landslide.

Due to the lack of social, economic, environmental and physical vulnerability data, only building and land use vulnerability assessments were carried out using SMCE model in our study. We found that $34.13 \%$ of the numbers of buildings were represented as high susceptibility class. We estimated as well that in high susceptibility class there was $39.9 \%$ from the governmental land use and $40.9 \%$ from the private.

The method presented here has a series of drawbacks, which should be taken into account. For instance, the landslide hazard map was only calculated from the occurrence of active landslides. Other landslide activities should also be included for future research. However, the use of landslide hazard index statistics in Khelvachauri is useful for ranking them in order of importance for landslide risk reduction measures. The method allows evaluating which causal factor is responsible for high susceptible and vulnerable of landslides. It should also be noted that the resulting landslide susceptibility value and the vulnerability were not static [15]. The landslide susceptibility map and vulnerability value should therefore be updated regularly since these indicators had temporal variability. For further study to improve the vulnerability assessment results, it is highly recommended that other factors such as river distance, number of population per household, climate data, history of landslide event, once become available, should be taken into account. This would make landslide data more reliable. This would make local (provincial and municipal) authorities accordingly produce logical landslide mitigation program.

\section{Acknowledgements}

This work was carried out under the auspices of the Ministry of Science and Technology of China (Grant number: 2013CB733404). The authors would like to thank Dr. C.J. Cees van Westen and Ms. Drs. N. C. Kingma with International Institute for Geo-Information Science and Earth Observation (ITC), University of Twente, the Netherlands for their kind suggestions and comments on the validation analysis. The authors would like to thank National Environmental Agency of Ministry of Environment and Natural Resources Protection of Georgia for providing various datasets used in this study.

\section{REFERENCES}

[1] A. Clerici, S. Perego, C. Tellini and P. Vescovi, "A Procedure for Landslide Susceptibility Zonation by the Conditional Analysis Method," Geomorphology, Vol. 48, No. 4, 2002, pp. 349-364. http://dx.doi.org/10.1016/S0169-555X(02)00079-X

[2] E. M. Lee and D. K. C. Jones, "Landslide Risk Assessment,” Thomas Telford, London, 2004. http://dx.doi.org/10.1680/lra.31715

[3] W. J. Kockelman, "Some Techniques for Reducing Landslide Hazards," Association of Environmental and Engineering Geologists, Vol. 23, No. 1, 1986, pp. 29-52

[4] UNDRO, “Mitigating Natural Disasters," Phenomena, Effects and Options United Nations, New York, 1991.

[5] C. J. Van Westen and M. T. J. Terlien, "An Approach towards Deterministic Landslide Hazard Analysis in GIS: A Case Study from Manizales, Colombia," Earth Surface Processes and Landforms, Vol. 21, No. 9, 1996, pp. 853868.

[6] V. Moon and H. Blackstock, “A Methodology for Assessing Landslide Hazard Using Deterministic Stability Models,” Natural Hazards, Vol. 32, No. 1, 2004, pp. 111134.

http://dx.doi.org/10.1023/B:NHAZ.0000026793.49052.87

[7] J. W. Godt, R. L. Baum, W. Z. Savage, D. Salciarini, W. H. Schulz and E. L. Harp, “Transient Deterministic Shallow Landslide Modeling: Requirements for Susceptibility And Hazard Assessments in a GIS Framework," Engineering Geology, Vol. 102, No. 3-4, 2008, pp. 214-226. http://dx.doi.org/10.1016/j.enggeo.2008.03.019

[8] A. Carrara, M. Cardinali, R. Detti, F. Guzetti, V. Pasqui and P. Reichenbach, "GIS Techniques and Statistical Models in Evaluating Landslide Hazard," Earth Surface Processes and Landforms, Vol. 16, No. 5, 1991, pp. 427445. http://dx.doi.org/10.1002/esp.3290160505

[9] L. Luzi and P. Floriana, "Application of Statistical and GIS Techniques to Slope Instability Zonation (1: 50,000 Fabriano Geological Map Sheet)," Soil Dynamics and Earthquake Engineering, Vol. 15, No. 2, 1996, pp. 83-94. http://dx.doi.org/10.1016/0267-7261(95)00031-3

[10] A. Burton and J. C. Bathurst, "Physically Based Modeling of Shallow Landslide Sediment Yield at a Catchment Scale,” Environmental Geology, Vol. 35, No. 2-3, 1998, pp. 89-99. http://dx.doi.org/10.1007/s002540050296

[11] F. Guzzetti, A. Carrarra, M. Cardinali and P. Reichenbach, "Landslide Hazard Evaluation: A Review of Current Techniques and Their Application in a Multi-Scale Study, Central Italy,” Geomorphology, Vol. 31, No. 1-4, 1999, pp. 181-216. http://dx.doi.org/10.1016/S0169-555X(99)00078-1

[12] J. Choi, H. J. Oh, J. S. Won and S. Lee, "Validation of an Artificial Neural Network Model for Landslide Susceptibility Mapping,” Environmental Earth Sciences, Vol. 60, 3, 2010, pp. 473-483. http://dx.doi.org/10.1007/s12665-009-0188-0

[13] B. Pradhan and S. Lee, "Regional Landslide Susceptibility Analysis Using Back-Propagation Neural Network Model at Cameron Highland, Malaysia,” Landslides, Vol. 7, No. 
1, 2010, pp. 13-30. http://dx.doi.org/10.1007/s10346-009-0183-2

[14] K. Sassa, S. Tsuchiya, K. Ugai, A. Wakai and T. Uchimura, "Landslides: A Review of Achievements in the First 5 Years (2004-2009),” Landslides, Vol. 6, No. 4, 2009, pp. 275-286. http://dx.doi.org/10.1007/s10346-009-0172-5

[15] E. A. Castellanos Abella and C. J. Van Western, “Generation of a Landslide Risk Index Map for Cuba Using Spatial Multi-Criteria Evaluation,” Landslides, Vol. 4, No. 4, 2007, pp. 311-325. http://dx.doi.org/10.1007/s10346-007-0087-y

[16] R. Chowdhury and P. Flentje, "Role of Slope Reliability Analysis in Landslide Risk Management," Bulletin of Engineering Geology and the Environment, Vol. 62, No. 1, 2003, pp. 41-46.

[17] S. Lee and J. A. Talib, "Probabilistic Landslide Susceptibility and Factor Effect Analysis,” Environmental Geology, Vol. 47, No. 7, 2005, pp. 982-990. http://dx.doi.org/10.1007/s00254-005-1228-z

[18] E. A. Castellanos Abella and C. J. Van Western, “Qualitative Landslide Susceptibility Assessment by Multicriteria Analysis: A Case Study from San Antonio del Sur, Guantánamo, Cuba,” Geomorphology, Vol. 94, No. 3-4, 2008, pp. 453-466. http://dx.doi.org/10.1016/j.geomorph.2006.10.038

[19] C. F. Chung and A. G. Fabbri, "Probabilistic Prediction
Models for Landslide Hazard Mapping," Photogrammetric Engineering \& Remote Sensing, Vol. 65, No. 12, 1999, pp. 1389-1399.

[20] J. Duan and G. E. Grant, "Shallow Landslide Delineation for Steep Forest Watersheds Based on Topographic Attributes and Probability Analysis,” In: J. P. Wilson and J. C. Gallant, Ed., Terrain Analysis-Principles and Applications, John Wiley \& Sons: New York, 2000, pp. 311329.

[21] S. Lee and N. T. Dan, "Probabilistic Landslide Susceptibility Mapping in the Lai Chau Province of Vietnam: Focus on the Relationship between Tectonic Fractures and Landslides,” Environmental Geology, Vol. 48, No. 6, 2005, pp. 778-787. http://dx.doi.org/10.1007/s00254-005-0019-x

[22] S. Lee, “Application of Likelihood Ratio and Logistic Regression Models to Landslide Susceptibility Mapping in GIS,” Environmental Management, Vol. 34, No. 2, 2004, pp. 223-232. http://dx.doi.org/10.1007/s00267-003-0077-3

[23] R. Dahal, S. Hasegawa, A. Nonomura, M. Yamanaka, T. Masuda and K. Nishino, "GIS-Based Weights-of-Evidence Modelling of Rainfall-Induced Landslides in Small Catchments for Landslide Susceptibility Mapping," Environmental Geology, Vol. 54, No. 2, 2008, pp. 314-324. http://dx.doi.org/10.1007/s00254-007-0818-3 